\title{
FETAL HAEMODINAMIC AND NEONATAL CEREBRAL CIRCULATION IN MATERNAL THREATENED PRETERM LABOR
}

\author{
G. Senatorova, O. Riga, A. Senatorova, A. Boychenko, I. Vasilyeva \\ Paediatrics, Kharkiv National Medical University, Kharkiv, Ukraine
}

Background and aims: The improvement of practical approach to cerebral hemodynamic disturbances in neonates starting from fetal period is important for prevent of hypoxic encephalopathy.

Methods: Prospective investigation of fetal and cerebral neonatal circulation was preformed on 36 neonates: I group - 13 infants with physiologic course maternal pregnancy and 20 ones - with maternal threatened preterm labor. Mean age of fetal circulation investigation was $34.1 \pm 4.0$ weeks.

Results: The statistically significant difference (Mann-Whitney U Test) were at medial cerebral artery (MCA): V max $47 \mathrm{~cm} / \mathrm{s}$ (I) and $42.8 \mathrm{~cm} / \mathrm{s}$ (II) [p=0.022]; Vmin $15.8 \mathrm{~cm} / \mathrm{s}$ (I) and $12.6 \mathrm{~cm} / \mathrm{s}$ (II) [p=0,000]. After birth in II group infants the resistance index (RI) in MCA was high 0.68(I) and 0.73(II) [p=0,008]. The nonparametric Spearman correlation for highlighting p-level $<0.05$ has shown a positive relation between Vmax umbilical artery and Vmin, Vmax, and IR in MCA in neonate $(\mathrm{R}=0.34)$.

Conclusions: We conclude that infants with maternal threatened preterm labor mothers have decreasing of cerebral hemodynamic speeds since intrauterine period. There is a relation between umbilical flow and cerebral circulation before and after birth. 